\title{
Prevalence of infection with Cryptosporidium parvum and Cyclospora cayetanensis among international travellers
}

Department of Infectious Diseases and Tropical Medicine, University of Munich, Germany

T Jelinek

M Lotze

S Eichenlaub

T Löscher

H D Nothdurft

Correspondence to: Dr Tomas Jelinek, Department of Infectious Diseases and Tropical Medicine, Leopoldstrasse 5, 80802 Munich, Germany.

Accepted for publication 29 May 1997

\begin{abstract}
Background-Cryptosporidium parvum and Cyclospora cayetanensis are recognised as possible pathogens of traveller's diarrhoea.

Aims-To identify the prevalence of $C$ parvum and Cyc cayetanensis in travellers returning from developing countries. Patients-Nine hundred and seventy eight stool samples were taken from 795 patients returning from developing countries.

Methods-Microscopy (iron-haematoxylin stain, SAF concentration, modified acid fast stain) and a commercially available enzyme linked immunosorbent assay (ELISA) kit for the detection of Cryptosporidium antigen in stool.

Results-Of the 795 patients in the study, 469 suffered from diarrhoea. Infection with Cyc cayetanensis could be detected in five subjects $(1.1 \%)$ by acid fast stain, and 13 patients $(2.8 \%)$ were infected with $C$ parvum. On evaluation, the antigen capture ELISA turned out to be clearly less sensitive for detection of $C$ parvum than microscopy. All patients with either $C$ parvum or Cyc cayetanensis infection suffered from watery diarrhoea.

Conclusions-C parvum and Cyc cayetanensis are not major causes of diarrhoea in international travellers. In cases of persistent watery diarrhoea, however, these pathogens should be taken into account in the differential diagnosis. (Gut 1997; 41: 801-804)
\end{abstract}

Keywords: diarrhoea; Cryptosporidium parvum; Cyclospora cayetanensis

Diarrhoea seems to be a more or less accepted part of the travelling experience for many tourists. This has some justification, as most episodes of traveller's diarrhoea are self limiting, and the pathogens responsible do not cause major harm to the intestines. However, some patients develop diarrhoea as the result of more obstinate pathogens, and continue to suffer from symptoms for a considerable time after their return home. On evaluation of the symptoms, two protozoa that only recently have been recognised as possible causes of traveller's diarrhoea should be considered: Cryptosporidium parvum and Cyclospora cayetanensis.
Cyc cayetanensis was first described in 1986 as a pathogen and is now recognised as a world wide cause of diarrhoea in humans. ${ }^{1}$ The most common clinical features caused by this parasite include watery diarrhoea, fatigue, anorexia, weight loss, and upper intestinal pain. ${ }^{2}$ Infection with Cyclospora appears to be common in some areas of the world: $6-18 \%$ of children in Lima, Peru, were found to be infected with the parasite but only $22 \%$ of these were symptomatic. ${ }^{3}$ It has been assumed that populations in endemic areas may be less susceptible to the organism than populations in nonendemic areas, who may suffer a $100 \%$ attack rate. ${ }^{3}$ A common source of infection appears to be contaminated water, ${ }^{2}$ and transmission rates seem to peak between April and September. ${ }^{2}{ }^{3}$ Various reports on Cyclospora infections in travellers have been published. ${ }^{12-13}$ However, to our knowledge, the actual prevalence of this pathogen among travellers returning from developing countries has not been investigated in a prospective study.

In addition to being a frequent cause of diarrhoea in HIV-infected patients and being the causative agent of several water-borne outbreaks of diarrhoea in recent years, $C$ parvum has been recognised as an important agent of traveller's diarrhoea. ${ }^{1}$ Clinically immunocompetent patients usually suffer from watery diarrhoea, occasionally accompanied by nausea, vomiting, weight loss, anorexia, and dehydration. The duration of symptoms and excretion of oocysts might last from 1 day to 8 weeks. ${ }^{14} 15$ In a review of pooled data from 78 studies, $6.1 \%$ of diarrhoeal illnesses in immunocompetent patients in developing countries were found to be due to $C$ parvum, compared with $2.1 \%$ in developed countries. ${ }^{16}$ In HIV-infected patients, the same study showed that $24 \%$ of diarrhoeal illnesses in developing countries and $13.8 \%$ in developed countries are caused by $C$ parvum. Reservoirs for infection of humans have been identified in calves, cats, and dogs, but faecal-oral person to person transmission remains very important. ${ }^{1718} C$ parvum has been identified repeatedly as the causative agent of watery diarrhoea in travellers. ${ }^{111} 15$ 19-28 However, there is still a lack of prospective studies investigating the epidemiology of $C$ parvum infection in international travellers.

Both Cyc cayetanensis and $C$ parvum can be diagnosed microscopically by using a modified acid fast stain. ${ }^{329}{ }^{30}$ Having a size of $8-10 \mu \mathrm{m}$ in diameter, the variably staining oocysts of $C y c$ cayetanensis (fig 1) are larger than the usually 


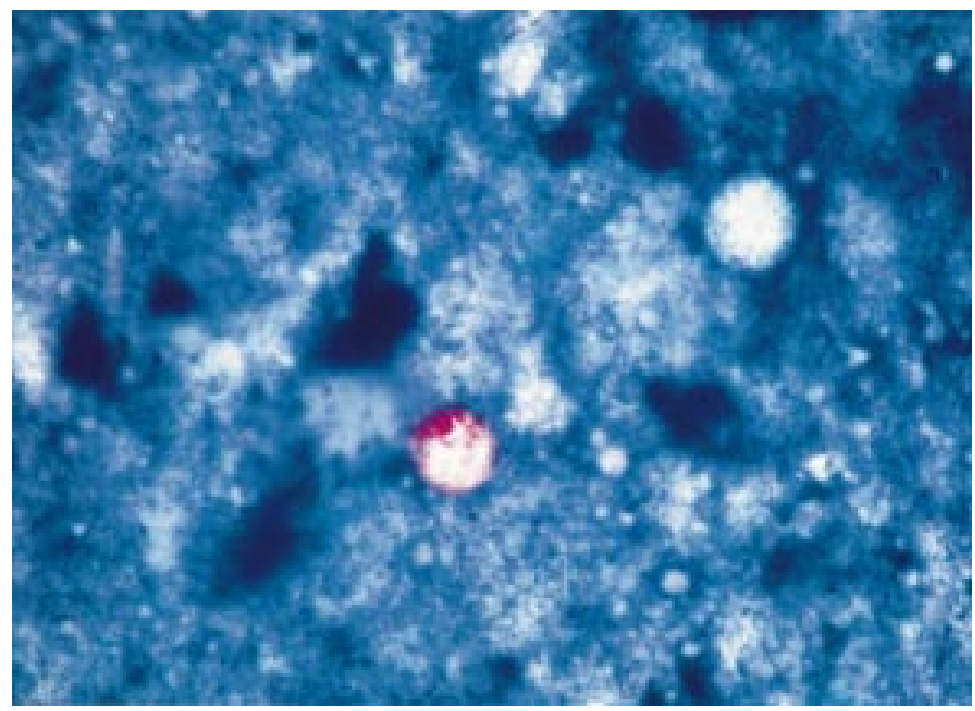

Figure 1: Cyclospora cayetanensis in stool samples from symptomatic travellers (modified acid fast stain, bright field microscopy, original magnification $\times 630)$.

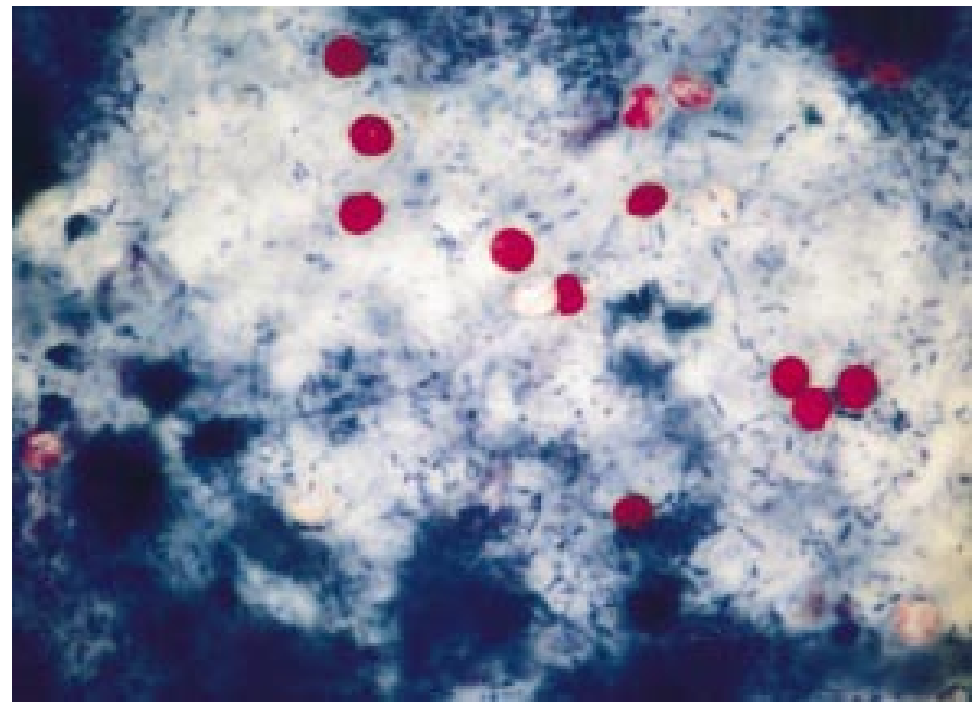

Figure 2: Cryptosporidium parvum in stool samples from symptomatic travellers (modified acid fast stain, bright field microscopy, original magnification $\times 630$ ).

nicely staining oocysts of $C$ parvum $(3-6 \mu \mathrm{m})$ (fig 2). In addition, oocysts of Cyc cayetanensis show blue autofluorescence under ultraviolet light. ${ }^{3}$ Enzyme linked immunosorbent assay (ELISA) kits for the detection of $C$ parvum oocysts in stools have been reported to have good sensitivity and specificity, ${ }^{31}{ }^{32}$ but microscopy remains currently the most reliable method for diagnosing Cyc cayetanensis from a stool sample.

To identify the prevalence of $C$ parvum and Cyc cayetanensis infection in travellers returning from developing countries, a prospective study was carried out at the travel clinic and outpatient department of the Department of Infectious Diseases and Tropical Medicine, University of Munich, Germany.

\section{Materials and Methods}

PATIENTS

From May to September 1995, 795 patients who presented with various medical complaints were recruited from our outpatient clinic. The main symptoms were diarrhoea in $469(59 \%)$, fever in $167(21 \%)$, and various skin problems in $83(10.4 \%)$, while $76(9.6 \%)$ wanted a post-travel medical check up but did not complain of any symptoms. All patients were German nationals returning from vacational trips abroad and gave their informed consent to the investigation.

METHODS

From the 795 patients, 978 stool specimens were collected and processed. All stool samples were investigated for ova and parasites by direct microscopy (iron-haematoxylin stain), the SAF (sodium acetate/acetic acid/formalin)/ethyl acetate concentration technique, iodine staining, and modified acid fast stain. ${ }^{329} 3033$ Each slide (sample volume approximately $10 \mu \mathrm{l}$ ) was read quantitatively by two experienced microscopists before being considered negative. A portion of every fresh stool sample was stored immediately at $-20^{\circ} \mathrm{C}$ and tested later by a commercially available antigen capture ELISA designed for the detection of Cryptosporidium oocysts (Alexon Inc, Mountain View, California, USA) according to the manufacturer's instructions, by one laboratory technician who was blinded to the results of the microscopy. If discordant results between microscopy and ELISA were obtained, both tests were repeated. Microscopy was defined as the reference for the final results; only samples with microscopically positive results for $C$ parvum were considered as positive. The definition "true positive", however, was extended to all patients who produced at least one microscopically positive stool specimen, even if they initially presented with a series of negative specimens. Statistical analysis was performed using the EPI-Info 6.0 (CDC, Atlanta, Georgia, USA and WHO, Geneva, Switzerland) software package.

\section{Results}

All 978 specimens from 795 patients were examined by microscopy and antigen capture ELISA. Altogether, 15 specimens from 13 patients $(1.6 \%)$ were considered positive for $C$ parvum and a further five specimens from five patients $(0.6 \%)$ were positive for Cyc cayetanensis. However, infection with $C$ parvum occurred in $2.8 \%$ of the 469 patients presenting with diarrhoea, while Cyclospora accounted for $1.1 \%$ of infections in these 469 symptomatic patients. All samples from the latter group were diagnosed by modified acid-fast staining. The same staining method was used as the "gold standard" for the diagnosis of $C$ parvum: of the initial specimens, eight were positive by microscopy and ELISA (table 1), and 782 were negative by both methods. Five specimens were positive by microscopy and negative by ELISA; these were considered to be false negative in the ELISA. One specimen was positive by the ELISA and negative by microscopy. This sample was initially considered to be a false positive in the ELISA. On re-presentation of the patient, two more samples were delivered and examined; they were now positive by both methods. Defining each microscopic result per 
TABLE 1 Comparison of microscopy and antigen capture enzyme linked immunosorbent assay (ELISA) for the detection of Cryptosporidium parvum in stool ( $n=978$ samples)

\begin{tabular}{lcc}
\hline & $\begin{array}{c}\text { All specimens } \\
(n=978)\end{array}$ & $\begin{array}{c}\text { Initial specimens } \\
(n=795)\end{array}$ \\
\hline Results & 9 & 7 \\
$\quad$ Microscopy +; ELISA + & 5 & 5 \\
$\quad$ Microscopy +; ELISA - & 1 & 1 \\
$\quad$ Microscopy -; ELISA + & 963 & 782 \\
$\quad$ Microscopy -; ELISA - & $9 / 14(64 \%)$ & $7 / 12(58 \%)$ \\
Sensitivity of ELISA $v$ microscopy & & \\
Sensitivity of both methods $v$ all true positivest & $10 / 15(67 \%)$ & $8 / 13(61 \%)$ \\
$\quad$ ELISA & $14 / 15(93 \%)$ & $12 / 13(92 \%)$ \\
$\quad$ Microscopy & \\
\hline
\end{tabular}

*Values are number of tests positive by ELISA or microscopy/number of microscopically positive tests.

†Values are number of tests positive by ELISA or microscopy/number of "true positive" tests. This includes specimens positive for $C$ parvum by microscopy as well as ELISA positive and microscopically negative specimens from patients with subsequent microscopically positive stool samples.

specimen as the gold standard, the ELISA reached a sensitivity of $58 \%$ compared with microscopy. The use of the definition for true positive patients (a single positive specimen in a row of negatives defines a patient as Cryptosporidium positive) did not change the sensitivity of the ELISA much $(61 \%)$, while microscopy of single specimens yielded good results with a sensitivity of $92 \%$. Very similar results were obtained for the evaluation of all 978 samples (table 1): the sensitivity of ELISA $v$ microscopy was $64 \%$, that of ELISA $v$ all true positives $67 \%$, and that of microscopy $v$ all true positives $93 \%$.

No other parasites carried by the patients investigated stained in the modified acid-fast stain, nor were any cross reactions of the antigen capture ELISA with other antigens observed. Of the 795 patients, 201 (25.3\%) carried at least one parasite other than Cyclospora or Cryptosporidium in the stool: 74 patients were infected with Giardia duodenalis (14 asymptomatic), 74 with Entamoeba dispar/ histolytica (43 asymptomatic), 73 with Blastocystis hominis (22 asymptomatic), 54 with Entamoeba coli (all asymptomatic), 53 with Endolimax nana (all asymptomatic), and 55 with a variety of other intestinal parasites (including Iodamoeba bütschlii, Trichomonas hominis, Chilomastix mesnili, Isospora belli, Ancylostoma duodenale/Necator americanus, Strongyloides stercoralis, Trichuris trichiura, Ascaris lumbricoides; 40 asymptomatic).

All five patients considered to be infected with Cyclospora presented with watery diarrhoea as the predominant medical complaint during or after the journey. The mean duration of symptoms was 19.8 days (range 11-32 days). Two patients complained of occasional spells of nausea and anorexia. Of the 13 patients infected with Cryptosporidium, ten presented with persistent watery diarrhoea as their sole complaint. The other three presented with diarrhoea and an itching exanthema on the arms and legs (two) or trunk (one). The mean duration of symptoms before presentation was 36.2 days (range 12-120 days) in these 13 patients. Four of the 13 patients infected with Cryptosporidium had visited India, three South East Asia (Thailand and Malaysia), two each South America (Venezuela and Brazil) and West Africa (The Gambia and Senegal), and one each Southern Africa (Zimbabwe) and Central America (Mexico). Of the five patients infected with Cyclospora, two each had been to Central America (Mexico and Guatemala) and India and one to South East Asia (Thailand) before the study. In comparison, 120 (25.6\%) of the 469 patients with traveller's diarrhoea had been to the Indian subcontinent, 96 $(20.5 \%)$ to East Africa (mostly Kenya), 76 $(16.2 \%)$ to South east Asia (predominantly Thailand), and $65(13.9 \%)$ to Central America. Presentation of patients positive for either Cryptosporidium or Cyclospora was evenly distributed throughout the study period (May to September 1995).

\section{Discussion}

Quick, simple and reliable tests are required for the screening of large numbers of patients for intestinal parasites. Acid fast staining, which is able to detect oocysts of Cyclospora and Cryptosporidium with satisfactory sensitivity, ${ }^{33}$ can be included in most routine parasitological laboratory procedures without much expenditure. As indicated by the low prevalence in the group of travellers investigated in this study $(1.6 \%$ for Cryptosporidium and $0.6 \%$ for Cyclospora), neither parasite appears to be a major cause of diarrhoea in international travellers. However, they should be considered as causative pathogens in patients with prolonged watery diarrhoea, since infection with $C$ parvum occurred in $2.8 \%$ of the 469 patients presenting with diarrhoea and Cyclospora accounted for $1.1 \%$ of these infections. Consideration of these pathogens is especially warranted because diagnosis can be made readily by acid fast stain, and treatment (at least of Cyclospora) is available. $^{34}$

ELISAs for the detection of $C$ parvum antigen in stool samples have recently been developed in several laboratories, ${ }^{31}{ }^{32}$ and some are now commercially available. To assess its usefulness in clinical and epidemiological settings, we evaluated one of these test kits. Compared with microscopic examination of stool samples, the ELISA turned out to be markedly less sensitive $(66.7 \% v 93.3 \%)$ at an optical density of $\geqslant 0.05$, as recommended by the manufacturer (table 1). The technical properties of an ELISA mean that many specimens can be processed and read by a single technician in a short period of time, thereby maintaining a level standard. Therefore the ELISA is potentially more suitable than microscopy in certain settings, especially in epidemiological surveys and in follow up examinations of patients known to be Cryptosporidium positive. However, although the small number of positives in the group investigated does not allow a definitive answer, the ELISA used in this investigation was clearly less sensitive than microscopic analysis of stool samples.

Watery diarrhoea was the main symptom in all patients positive for either Cyclospora or Cryptosporidium. An interesting, and somewhat unexpected, finding was the occurrence of an itching exanthema in three patients with $C$ parvum infection. The mean duration of symptoms was quite long: 19.8 days for patients 
positive for Cyclospora and 36.2 days for those positive for Cryptosporidium. Some patients reported the presence of diarrhoeal and other gastrointestinal symptoms for up to 120 days. All of these "long-sufferers" had stool samples tested microscopically at various times without any positive result. These findings agree with findings that patients with Cyclospora or Cryptosporidium infection frequently remain undiagnosed because of a lack of routine laboratory procedures to identify these pathogens.

The data do not connect a particular travel destination with the acquisition of either Cyclospora or Cryptosporidium. The Indian subcontinent and Indonesia have been reported as being high risk areas for both pathogens. ${ }^{1269}$ However, a sizeable number of our patients acquired the respective infection in Africa or the Americas. The results of the present investigation show that infection with either $C y$ clospora or Cryptosporidium appears to be a fairly rare event in international travellers. However, an examination of fresh stool samples by modified acid fast staining could be useful for patients with prolonged watery diarrhoea after a journey to a developing country.

1 Adal K. From Wisconsin to Nepal: Cryptosporidium, Cyclospora, and microsporidia. Current Opinion in Infectious Cyclospora, and micros

2 Hoge C, Shlim D, Rajah R, Triplett J, Shear M, Rabold J, Echeverria P. Epidemiology of diarrhoeal illness associated with coccidian-like organisms among travellers and foreign residents in Nepal. Lancet 1993;341:1308-12

3 Ortega Y, Sterling C, Gilman R, Cama V, Diaz F Cyclospora species: a new protozoan pathogen of humans N Engl f Med 1993;328:1308-12.

4 van Gool T, Dankert J. Three emerging protozoal infections in The Netherlands: Cyclospora, Dientamoeba, and 155-60.

5 Lontie M, Degroote K, Michiels J, Bellers J, Mangelschots E, Vandepitte J. Cyclospora sp.: a coccidian that causes diarrhoea in travellers. Acta Clin Belg 1995;50:288-90.

6 Lammers HA, van Gool T, Eeftinck Schattenkerk JK. Two patients with diarrhea caused by Cyclospora cayetanensis patients with diarrhea caused by Cyclospora cayetanensis 140:890-2

7 Junod C, Deluol AM, Cosnes J, Bauer P. Cyclospora, a new coccidium agent of travelers' diarrhea. 11 cases [letter] Presse Med 1994:23:1312.

8 Deluol AM, Junod C, Poirot JL, Heyer F, Y Ng, Cosnes J. Travellers diarrhea associated with Cyclospora sp. $\mathscr{f}$ Eukaryot Microbiol 1994;41:32

9 Butcher AR, Lumb R, Coulter E, Nielsen DJ. Coccidian/ cyanobacterium-like body associated diarrhea in an Australian traveller returning from overseas. Pathology 1994;26 59-61.

10 Anonymous. Diarrhoea associated with Cyclospora species. Commun Dis Rep CDR Wkly 1993;3:103.
11 Black RE. Epidemiology of travelers' diarrhea and relative importance of various pathogens. Reviews of Infectious Diseases 1990;12:S73-S79.

12 Pollock R, Bendall R, Moody A, Chiodini P. Traveller's diarrhoea associated with cyanobacterium-like bodies. Lancet 1992;340:556-7.

13 Himy O, Villard O, Kremer M. Cyclosporidia: a general review. Fournal of Travel Medicine 1995;2:33-6.

14 Egger M, Mausezahl D, Odermatt P, Marti HP, Tanner M. Symptoms and transmission of

15 Martins C, Guerrant R. Cryptosporidium and Cryptosporidiosis. Parasitology Today 1995;11:434-6.

16 Adal K, Sterling C, Guerrant R. Cryptosporidium and related species. In: Blaser M, Smith P, Ravdin J, eds. Infections of the gastrointestinal tract. New York: Raven Press,

17 Lengerich E, Addiss D, Marx J, Ungar B, Juranek D. Increased exposure to cryptosporidia among dairy farmers in Wisconsin. F Infect Dis 1993;167:1252-5.

18 Newman R, Wuhib T, Lima A, Guerrant R, Sears C. Enviromental sources of Cryptosporidium in an urban slum in Notheastern Brazil. Am f Trop Med Hyg 1993;49:270-5.

19 Black RE. Pathogens that cause traveller's diarrhea in Latin America and Africa. Review of Infectious Diseases 1986;8: S131-5.

20 Flegg PJ. Cryptosporidium in travellers from Pakistan [letter]. Trans R Soc Trop Med Hyg 1987;81:171.

21 Gatti S, Cevini C, Bruno A, Bernuzzi AM, Scaglia $M$. Cryptosporidiosis in tourists returning from Egypt and the Cryptosporidiosis in tourists returning from Egypt and the
Island of Mauritius [letter]. Clinical Infectious Diseases 1993;16:344.

22 Jokipii L, Pohjola S, Jokipii AM. Cryptosporidium: a frequent finding in patients with gastrointestinal symptoms. Lancet 1983;ii:358-61.

23 Jokipii L, Pohjola S, Jokipii AM. Cryptosporidiosis associated with traveling and giardiasis. Gastroenterology 1985;89: 838-42.

24 Keusch GT, Hamer D, Joe A, Kelley M, Griffiths J, Ward H. Cryptosporidia: who is at risk? Schweiz Med Wochenschr 1995;125:899-908.

25 Ma P, Kaufman DL, Helmick CG, AJ DS, Navin TR. Cryptosporidiosis in tourists returning from the Caribbean [letter]. N Engl f Med 1985;312:647-8.

26 Soave R, Ma P. Cryptosporidiosis. Traveller's diarrhea in Soave R, Ma P. Cryptosporidiosis. Traveller's
two families. Arch Intern Med 1985;145:70-2.

27 Sterling CR, Seegar K, Sinclair NA. Cryptosporidium as a causative agent of traveller's diarrhea [letter]. F Infect Dis 1986;153:380-1.

28 Ungar BL, Mulligan M, Nutman TB. Serologic evidence of Cryptosporidium infection in US volunteers before and during Peace Corps service in Africa. Arch Intern Med 1989;149:894-7.

29 Garcia LS, Current WL. Cryptosporidiosis: clinical features and diagnosis. Crit Rev Clin Lab Sci 1989;27:439-60.

30 Long E, White E, Carmichel W, Quinlisk P, Raja R, Swisher B, Daugharty H, Cohen M. Morphologic and staining characteristics of a cyanobacterium-like organism associated with diarrhoea. $\mathcal{F}$ Infect Dis 1991;164:199-202.

31 Rosenblatt J, Sloan L. Evaluation of an enzyme-linked immunosorbent assay for detection of Cryptosporidium
spp. in stool specimens. $\mathcal{F}$ Clin Microbiol 1993;31:2944-6.

32 Newman R, Jaeger K, Wuhib T, Lima A, Guerrant R, Sears C. Evaluation of an antigen capture enzyme-linked immunosorbent assay for detection of Cryptosporidium oocysts. 7 Clin Microbiol 1993;31:2080-4.

33 Garcia L, Bruckner D. Diagnostic medical parasitology. Washington DC: American Society of Microbiology, 1993.

34 Hoge CW, Shlim DR, Ghimire M, Rabold JG, Pandey P, Walch A, Rajah R, Gaudio P, Echeverria P. Placebocontrolled trial of co-trimoxazole for Cyclospora infections among travellers and foreign residents in Nepal. Lancet 1995;345:691-3. 